\title{
CAPSULE ENDOSCOPY IN CLINICAL PRACTICE - four years of experience from a single center
}

\author{
Gustavo Pignaton de FREITAS, Newton TEIXEIRA and Gregorio FELDMAN
}

\begin{abstract}
Capsule endoscopy is a diagnostic method of increasing use nowadays, with various applications such as, evaluation of obscure gastrointestinal bleeding, chronic diarrhea and anemia. The experience of 4 years is reported in a retrospective review of 109 medical records to determine the main indications and the most common diagnostic findings and the percentage of positive studies. The main indications were obscure bleeding in $65 \%$, chronic anemia in $8 \%$. Vascular lesions in $33 \%$, being that, hematocistic spot was found in $53 \%$ of studies. The location of active bleeding was possible in five patients $(4.5 \%)$. Capsule endoscopy shows a high diagnostic yield in obscure bleeding.
\end{abstract}

HEADINGS - Capsule endoscopy. Gastrointestinal hemorrhage. Angiodysplasia.

\section{INTRODUCTION}

The capsule endoscopy $(\mathrm{CE})$ is a method of imaging the gastrointestinal tract using a wireless swallowable capsule which transmits images to a data recorder while this device goes through the small bowel propelled by natural peristalsis. CE was introduced in 2000, and until now more than 700 studies have been published. According to reports by the manufacturer (Given Imaging Ltd.), more than 650,000 examinations have been performed around the world ${ }^{(2)}$.

$\mathrm{CE}$ is a method of increasing use in the diagnostic work-up of obscure gastrointestinal (GI) bleeding. It is also used in the evaluation of patients with overt GI hemorrhage of unknown origin after non diagnostic esophagogastroduodenoscopy (EGD) and colonoscopy.

Although most of GI bleedings are easily diagnosed, nearly $10 \%$ of all bleedings remain obscure after initial evaluation. Between $28 \%$ to $45 \%$ of obscure bleeding are located at the small intestine. The angiodysplasia comprises $30 \%$ to $40 \%$ of these cases of bleeding ${ }^{(5)}$.

$\mathrm{CE}$ is not restricted to the uses mentioned above; the method has also other applications such as: evaluation of patients with suspected Crohn's disease, chronic diarrhea, evaluation of refractory iron deficiency anemia, abdominal pain, polyposis syndromes, celiac disease and screening for small bowel tumors. Considering that $\mathrm{CE}$ is a minimally invasive method, it can also be used in the evaluation of esophageal disorders, such as esophageal varices and Barrett's esophagus.

To our knowledge, this is the largest casuistry ever reported in Brazil, herein lays its importance.
To describe demographic patterns in patients who underwent capsule enteroscopy. To determine the main indications and the most common diagnostic findings in this casuistry and the percentage of positive studies.

\section{METHODS}

Review of medical records of patients who underwent capsule endoscopy from February 2005 to June 2009 in a private Gastrointestinal Endoscopy Unit in Rio de Janeiro, RJ, Brazil. Every patient referred to this service had to present a summary of their medical records, even as endoscopic and radiological exams related to the clinical setting. Some patients with GI bleeding also showed scintigraphic exams. Patients were referred by physicians from other hospitals and even from other cities. Thus, it was not possible to keep track of the outcome of these patients. The following variables were analysed: age and sex of patients, indication of the study, diagnosis after completion of the study, determine the percentage of positive studies either general or specific for bleeding. $\mathrm{CE}$ examinations were performed after a fasting of 8 hours. The institution used a wireless CE system by Given Imaging Ltd.

\section{RESULTS}

To date, 118 capsule studies have been performed in 109 patients. Most patients were female (57\%). The average age was 59.6 years, ranging from 15 to 97 years. The indications included obscure bleeding in $65 \%$, chronic anemia in $8 \%$, evaluation of diarrhea in $7 \%$,

Institution: Gastroendo Endoscopia Especializada - Rio de Janeiro, RJ, Brasi

Correspondence: Dr. Gustavo Pignaton - Rua Silveira Martins, 40 apt. 307 - Flamengo - 22221-000 - Rio de Janeiro, RJ, Brasil. E-mail: guspignaton@gmail.com 
abdominal pain in $6 \%$, evaluation for inflammatory bowel disease in nearly $3 \%$, screening for polyps in 3\% (Table 1 ).

Vascular lesions were the most frequent diagnosis in $32 \%$ of studies, followed by normal results in $14 \%$ and erosions along the small bowel in 7\%. The most common vascular lesion was the hematocystic spot in $53 \%$, followed by vascular ectasia in $22 \%$ of studies. Small bowel tumor was found in $4 \%$ of studies. The percentage of positive results was $86.5 \%$. The location of a source of active bleeding was possible in five patients $(4.5 \%)$. Ten cases $(9.2 \%)$ have lesions with a high potential for bleeding (P2 of Saurin's classification). In 6.4\% of studies, the findings were within the reach of conventional EGD, obviating the need of CE.

Considering only the patients $(n=70)$ whose indication for undergoing capsule endoscopy was GI bleeding, vascular lesions represent $48 \%$, followed by no findings in $14 \%$, tumors in $11 \%$, erosions along the small bowel in $9 \%$ and lesions within the range of EGD in 7\%. Phlebectasias comprise only $9 \%$ of the vascular disorders, such lesions have a low risk of bleeding (P0 Saurin's classification).

Among patients $(n=8)$ with diarrhea the exam was not suggestive of any diagnosis in $87.5 \%$, while findings consistent with Crohn's disease were found in $12.5 \%$.

Among patients $(n=8)$ who underwent $C E$ for diagnostic evaluation of anemia, $75 \%$ presented vascular lesions, mainly vascular ectasias. Two patients presented infiltrative lesion in the jejunum.

Among patients $(n=6)$ who underwent CE for diagnostic evaluation of abdominal pain, vascular lesions represent $40 \%$ and a normal study in $40 \%$.

Patients were divided into two groups: Group 1 consists of 50 patients under 60 years and group 2 that comprises 59 patients over 60 years. The lesions most commonly found in both groups were those of vascular origin. In group 1, vascular lesion was the diagnosis in $26 \%$ of studies. While in group 2, vascular lesion was also the most frequent in $31 \%$

TABLE 1. Descriptive analysis of patients undergoing capsule endoscopy examination

\begin{tabular}{cccc}
\hline Variables & & $\mathrm{n}$ & $\%$ \\
\hline Sex & Male & 48 & $44 \%$ \\
Age & Female & 61 & $56 \%$ \\
& $0-20$ years & 5 & $5 \%$ \\
& $21-40$ & 8 & $7 \%$ \\
& $41-60$ & 37 & $34 \%$ \\
Indications & $61-80$ & 47 & $43 \%$ \\
& $>81$ & 12 & $11 \%$ \\
& Bleeding & 68 & $65 \%$ \\
& Anemia & 8 & $8 \%$ \\
& Diarrhea & 7 & $7 \%$ \\
& Abdominal pain & 6 & $5.5 \%$ \\
& No findings & 15 & $14 \%$ \\
& Vascular lesion & 36 & $33 \%$ \\
& Submosis & 6 & $5 \%$ \\
& SB Erosive lesions & 9 & $8 \%$ \\
& SB tumor & 5 & $4 \%$
\end{tabular}

SB: small bowel of studies. Thus, the most common findings of $\mathrm{CE}$ were not different in regards to age.

The retention of capsule in the small bowel occurred in three patients $(2.5 \%)$. Three patients needed the capsule to be run through the pylorus with endoscopy aid, other three patients needed to repeat CE due to poor bowel cleansing.

\section{DISCUSSION}

CE represents a major advance in the study of small bowel disease since it allows images of otherwise unreachable areas. $\mathrm{CE}$ is a safe, minimally invasive, reliable technique, which is well accepted and tolerated by the patients. This device has a high diagnostic yield compared to other diagnostic modalities when it comes to investigation of the small bowel.

Enns et al. ${ }^{(2)}$ report the results of a study with 226 patients who underwent $\mathrm{CE}$ over a obscure bleeding in $74 \%$ of studies, and the second one was abdominal pain in $8 \%$. In this casuistry, 85 patients (representing $51 \%$ of studies) presented abnormalities. The most common lesions were of vascular origin in $61 \%$ of cases. These results are similar to those described in this study.

Tang et al. ${ }^{(5)}$ performed a retrospective investigation of 47 cases of obscure GI bleeding with CE from a single center. The general diagnostic yield was $63 \%$. The most common lesions were angioectasia and ulcers of the small bowel. In $17 \%$ of cases the bleeding source was within reach of the standard endoscopy, thus obviating the need of further tests. Overall retention rate is $1.4 \%$. In this casuistry, in only $6.4 \%$ of our cases, the lesions were reachable by EGD. This might be related with the good quality of endoscopy services in our midst. Retention rate in this study is somewhat higher, what may be explained by the low availability of patency capsule.

Kav et al. ${ }^{(3)}$ reported their 5 years experience with CE. A total of 120 studies were performed, with male predominance $(62.5 \%)$. The average age was 47 years. The main indications were obscure GI bleeding in 57\% and diarrhea in 15\%. No abnormalities were found in $22.5 \%$ of patients.

Makins et al. ${ }^{(4)}$ reported a study with 100 patients who underwent $\mathrm{CE}$ during a period of 2 years. The mean age of their patients was 39.5, and there was predominance of males. Most common indications for CE were: bleeding in 23 subjects, anemia in 24 subjects, assessment of Crohn's disease in 21 subjects and abdominal pain in 16 cases. Most common diagnosis were: small bowel ulcers in 27 subjects, angiodysplasia in 22 cases and no findings over the small bowel in 21 cases. In our casuistry, there was female predominance and a higher average age as opposed to the studies of Kav et al..$^{(3)}$ and Makins et al. ${ }^{(4)}$. The higher incidence of vascular lesions may be explained by the higher age of our patients.

Bakshi et al ${ }^{(1)}$ performed a study with 27 patients who underwent $\mathrm{CE}$ over a period of 2 years. CE showed no abnormalities in $59 \%$ of patients. A diagnosis of Crohn's disease was obtained in $11 \%$ of patients. Diagnostic yield of CE was higher for GI hemorrhage in comparison with other indications.

Capsule endoscopy is not available in the public health system of our city. In our midst, balloon enteroscopy is 
unavailable, and then it was rather difficult to perform a comparison with other tests.

\section{CONCLUSION}

The $\mathrm{CE}$ is a recognized diagnostic method in the evaluation of bleeding of obscure origin. In the casuistry presented, the obscure bleeding was the main clinical indication and vascular lesions were the most frequent diagnosis. Since the group consists mainly of older individuals, this might explain the higher occurrence of angiodysplasia. The high diagnostic yield of CE coupled with its low invasiveness turn it an indispensable tool for the gastroenterologist. The ocurrence of impaction is higher than in literature; however it is still quite low.

Pignaton G, Teixeira N, Feldman G. Cápsula endoscópica na prática clínica - quatro anos de experiência de um centro. Arq Gastroenterol. 2011;48(3): 220-2.

RESUMO - A endoscopia por cápsula é um método cada vez mais empregado na prática clínica, com diversas aplicações tais como: investigação de sangramento gastrointestinal obscuro, diarreia e anemia. A experiência de 4 anos é relatada em revisão retrospectiva de 109 registros médicos objetivando determinar as indicações e achados mais comuns e o percentual de exames positivos. As principais indicações foram: sangramento gastrointestinal obscuro em $65 \%$, anemia crônica em $8 \%$, lesões vasculares em $33 \%$ e a mancha hematocística foi observada em $53 \%$ dos estudos. A localização do sangramento ativo foi possível em 4,5\% dos casos. A endoscopia da cápsula demonstrou bom rendimento diagnóstico no sangramento obscuro.

DESCRITORES - Endoscopia por cápsula. Hemorragia gastrointestinal. Angiodisplasia.

\section{REFERENCES}

1. Bakshi E, Ashkenazi I, Katzenell U, Cohen O, Niv Y, Bar-Dayan Y. Wireless capsule endoscopy in Israeli Defense Force: two years of experience. Mil Med. 2009;174:991-5.

2. Enns R, Go K, Chang H, Pluta K. Capsule endoscopy: a single-centre experience with the first 226 capsules. Can J Gastroenterol. 2004;18:555-8.

3. Kav T, Bayraktar Y. Five years' experience with capsule endoscopy in a single center. World J Gastroenterol. 2009;15:1934-42.
4. Makins R, Blanshard C. Guidelines for capsule endoscopy: diagnoses will be missed. Aliment Pharmacol Ther. 2006;24:293-7.

5. Tang SJ, Christodoulou D, Zanati S, Dubcenco E, Petroniene R, Cirocco M, Kandel G, Haber GB, Kortan P, Marcon NE. Wireless capsule endoscopy for obscure gastrointestinal bleeding: a single-centre, one-year experience. Can J Gastroenterol. 2004;18:559-65. 